\title{
QUANDO O DESCOBRIMENTO NÃO É APENAS HISTÓRIA, MAS REFLEXÃO: \\ ABEL POSSE E A UMA TRILOGIA PARA PENSAR A INVASÃO DA AMÉRICA
}

\section{WHEN THE DISCOVERY IS NOT ONLY HISTORY, BUT REFLECTION: ABEL POSSE AND A TRIOLOGY TO THINK AMERICA'S INVASION}

\author{
Phelipe de Lima Cerdeira ${ }^{1}$ \\ Jucelia Hurtiah de Oliveira Pires ${ }^{2}$
}

\begin{abstract}
Resumo: Este artigo apresenta uma leitura da Trilogia do Descobrimento de Abel Posse, composta pelos romances Daimón (1978), Los perros del paraíso (1983) e El largo atardecer del caminante (1992). Demonstrar-se-á como o projeto ficcional de Posse oscila do caráter mais desconstrucionista apregoado pelo chamado novo romance histórico (MENTON, 1993) até um ponto em que a ficção está mais a serviço de uma mediação para (re)pensar o que havia sido oficializado. São circunscritas à fundamentação teórica contribuições de críticos como Gilmei Francisco Fleck (2008, 2017), Marilene Weinhardt (2006, 2011), Antonio Roberto Esteves (2017), Noé Jitrik (1995), Phelipe Cerdeira (2019), entre outros.
\end{abstract}

Palavras-chave: Ficção histórica; Literatura argentina; Romance histórico de mediação; Abel Posse.

Abstract: This article presents a reading of Abel Posse's Trilogy of Discovery, composed by the novels Daimón (1978), Los perros del paraíso (1983) and El largo atardecer del caminante (1992). It will be demonstrated how Posse's fictional project oscillates from a more deconstructionist character to a point where fiction is more at the service of a mediation to (re)think what had been made official. Contributions by critics such as Gilmei Francisco Fleck (2008, 2017), Marilene Weinhardt (2006, 2011), Antonio Roberto Esteves (2017), Noé Jitrik (1995), Phelipe Cerdeira (2019), among others.

Keywords: Historical fiction; Argentine literature; Historical novel of mediation; Abel Posse.

\section{Introdução}

\footnotetext{
1 Doutor em Letras - Estudos Literários pela Universidade Federal do Paraná. Realiza estágio de pósdoutoramento em Literatura Comparada na Universidade do Oeste do Paraná (UNIOESTE) sob a supervisão do professor doutor Gilmei Francisco Fleck. Pesquisador integrante do Grupo de Pesquisa "Ressignificações do passado na América: processos de leitura, escrita e tradução de gêneros híbridos de história e ficção - vias para descolonização". E-mail: phelipecerdeira@gmail.com

${ }^{2}$ Mestranda em Letras - Linguagem e Sociedade pela Universidade do Oeste do Paraná, sob a orientação do professor doutor Gilmei Francisco Fleck e co-orientação do professor doutor Phelipe de Lima Cerdeira. Professora da Educação Básica nas redes pública e privada, ministrando aulas de língua portuguesa e língua espanhola. Integra o Grupo de Pesquisa "Ressignificações do passado na América: processos de leitura, escrita e tradução de gêneros híbridos de história e ficção - vias para descolonização”. E-mail: hurtyake@ hotmail.com
} 
¡Apoyadnos!

En vez de la azada os encontraréis con las manos llenas de dulces tetitas. Trabajará la indiada, vosotros reposaréis. (POSSE, 1989, p. 243).

Pensar os múltiplos encontros entre os discursos ficcional e histórico demonstra ser uma das constantes possíveis para os estudos da crítica da literatura nas últimas décadas, justificando o que María Cristina Pons chama de "[...] un explosivo cultivo del género" (PONS, 1996, p. 97). Ainda que tal cotejo seja uma das possibilidades para pensar o texto literário, parece salutar observar que tal predominância nas Humanidades tem, em uma primeira instância, sinérgica relação com o interesse de desconstrução dos macrorrelatos a fim de que a perspectiva tratada não seja meramente a dos vencedores, mas, de alguma maneira, também a dos vencidos. Entre diálogos, fissuras e soslaios (CERDEIRA, 2019), os encontros entre ficção e história apontam as sinuosidades dos discursos e a capacidade humana para (se) narrar.

Extraída, assim, do romance Los perros del paraíso (1983), a epígrafe que abre a seção inicial deste artigo não apenas ilustra o compromisso de dar vazão àqueles que foram escamoteados pelos relatos oficiais, mas, ao mesmo tempo, fundamenta o exercício de reflexão de escritores como o argentino Abel Posse, dispostos a fissurar as fronteiras entre a presunçosa civilização e a sentenciada barbárie. A partir da seleção de três romances do escritor cordobês - Daimón (1978), Los perros del paraíso (1983) e El largo atardecer del caminante (1992) -, lidos por parte da fortuna crítica como a Trilogia do Descobrimento, buscar-se-á uma aproximação inicial $^{3}$ para evidenciar como Posse dosa o seu projeto diegético ao longo das décadas (do primeiro ao terceiro romance, tem-se quase vinte e cinco anos), experimentando distintas gradações ao interseccionar os discursos histórico e ficcional.

Em cada uma das obras, pouco a pouco, a temporada de dicotomias se esvai, pulverizando fronteiras e dando lugar às ambiguidades. Dito de outra maneira, Posse encontra logo no início do terceiro romance, El largo atardecer del caminante, uma metáfora para relativizar qualquer afirmação taxativa. Ao (re)construir a figura histórica Alvar Núñez Cabeza de Vaca ao longo de um caminho de um narrador autodiegético ciente das trampas e

\footnotetext{
${ }^{3}$ A menção quanto sobre o artigo ser uma aproximação inicial para ler e pensar os três romances enquanto Trilogia do Descobrimento se deve ao fato de a dissertação de mestrado Uma análise do romance histórico contemporâneo de mediação e a poética do descobrimento (UNIOESTE), de autoria de Jucelia Hurtiah de Oliveira Pires, estar em pleno desenvolvimento.
} 
dos riscos provocados pela chamada História com h maiúsculo, os leitores de Posse também poderão questionar se ainda é viável ser somente "boi" ou "águia":

\begin{abstract}
Desde niño, y tal vez por el orgullo de los relatos de mi madre, la jerazana, quise que mi vida fuese precisamente como colores de seda flameando sobre el gris de la mediocridad.

- Tendrás que elegir: ser buey, o águila como tu abuelo, el Vera que sometió las Canarias... - díjome [sic] una vez mi madre cuando yo me reponía del sarpullido febril que suele acometer a todo niño (había omitido recordar a mi padre, sólo se refirió al abuelo terrible). Nunca olvidé esas palabras. Ella me quería fuerte, águila. En realidade no me daba mucho para elegir más que entre los extremos. (POSSE, 1992, p. 15, grifos nossos).
\end{abstract}

A escolha pelo nome de Abel Posse e, como consequência, pela sua Trilogia do Descobrimento não se dá de maneira fortuita. Além de apontar o critério comum de interesse dos dois pesquisadores, revela-se a oportunidade de coadunar em uma leitura compartilhada experiências distintas para avaliar o texto literário e, especialmente, a produção contemporânea de ficção histórica argentina. Interessa-nos, pois, frisar a relevância do nome de Posse para exemplificar ao menos três pontos-chave: o primeiro, quanto ao seu espaço de atuação em um dado campo intelectual e de poder (BOURDIEU, 1990, 2002), ponderando a respeito de uma eventual circunscrição ao tropo literário Argentum Córdoba ${ }^{4}$, haja vista que, mesmo nascendo na província de Córdoba, a sua relação e inserção para pensar a literatura no País do Prata provenha majoritariamente de lentes centralizadoras e centralizantes; o segundo, no que concerne à relação de Posse com a chamada geração da nova narrativa argentina; o terceiro, que ganhará uma seção específica neste artigo, pela capacidade elástica de testar o entrelaçamento entre ficção e história, transgredindo a simplificação de rótulos para pensar a modalidade narrativa ficcional interessada pelo substrato histórico e, ainda, valorizando as transformações sofridas no processo de composição diegética. Ao longo de nossa leitura, ficará mais evidente como o autor de Daimón passa da desconstrução e do questionamento do plano histórico ao um tom mais apaziguador.

Independentemente de qual seja o romance da trilogia, o projeto ficcional de Posse não prevê a viabilidade de pensar a história via ficção sem ao menos suspeitar. Tal como afirmado por Luis Sáinz de Medrano em um evento de homenagem realizado a Abel Posse, fica

\footnotetext{
${ }^{4} \mathrm{O}$ tropo literário Argentm Córdoba diz respeito a uma hipótese de leitura para pensar as produções de ficção histórica argentina para além de um viés cêntrico-portenho (CERDEIRA, 2019). Desenvolvida enquanto cerne argumentativo-crítico de uma tese de doutorado, a perspectiva busca ser ampliada à medida que escritores e obras são lidas a partir desta inserção. Mais informações sobre o trabalho mencionado na sessão de referências.
} 
proeminente o dado de que "[...] en el siglo XX, afirmar que la historia es madre de la verdad resulta una idea asombrosa." (SÁENZ DE MEDRANO, s. n.). Mais uma vez, na terceira obra da trilogia, o foco narrativo parece dar conta de relativizar a objetividade histórica, reforçando o quanto o horizonte factual também acaba estando à mercê de uma praxe específica: “[...] sólo hay historia en lo grandilocuente, en lo visible, en actos que terminan en catedrales y desfiles. Por eso es tan banal el sentido de la historia que construyó para consumo oficial." (POSSE, 1992, p. 60, grifos nossos).

Para refletir a respeito de como Posse estabelece as suas diegeses, faz-se produtiva uma incursão inicial para pensar a tradição argentina de relacionar ficção e história, fundamentando alguns dos caminhos responsáveis para o desenvolvimento da chamada nova narrativa argentina.

\section{Más allá de este mundo: a tradição argentina de enlaçar ficção e história}

Não foi apenas o processo de invasão e colonização oferecido pelas potências ultramarinas europeias que influenciou diretamente a maneira como se lê o passado, o presente e o futuro no dito novo mundo e, efetivamente, na Argentina. No ensaio La narrativa histórica de escritoras latinoamericanas (2004), atenta à reflexão do desenvolvimento de ficções históricas de autoria feminina em diferentes campos literários na América, a crítica uruguaia Gloria da Cunha já salientava o quanto

[a]l promediar el siglo XX comienza a hacer eclosión, paralelamente, innovativas técnicas narrativas y profundos cambios ideológicos. Estos propician la toma de conciencia del valor de la historia y aquéllas proporcionan nuevas modas para convertir la narrativa histórica en un eficaz instrumento para cuestionarla (DA CUNHA, 2004, p. 15, grifos nossos).

É certo afirmar que o ímpeto para (re)contar a história a partir da literatura e dar voz para quem foi silenciado não é um afã latino-americano que evidenciou uma das facetas do chamado boom e as posteriores correntes literárias surgidas após os anos sessenta, tal qual se pode observar diante do desenvolvimento e das transformações sofridas pelo romance histórico. Consagrada pelo escocês Sir Walter Scott no início do século XIX a partir das obras Waverley (1814) e Ivanhoé (1819), essa modalidade foi rapidamente inserida no plano narrativo dos espaços defenestrados por figuras históricas como Cristóvão Colombo, Hernán Cortés, Cabeza de Vaca, entre outros. No dito novo continente, no entanto, mais do que gozar 
o papel de ajudar a forjar uma ideia romântica e encapsulada de nação, tal produção ficcional - décadas depois - passou a desempenhar também a possibilidade de manifestar a visão de uma história outra (MIGNOLO, 2003) e, ao mesmo tempo, de ponderar a quebra de uma racionalidade cristalizada ao redor não apenas em torno do vencedor, mas de uma aspiração impossível de ser atingida em um território habitado por um real maravilhoso. Não se trata de uma evidente e direta alusão a Alejo Carpentier e ao seu El reino de este mundo (1949), mas a soluções do próprio Posse ao longo da trilogia para hibridizar e demonstrar as ambiguidades das figuras históricas. Valeria exemplificar com o jogo proposto para a condição do próprio descobridor-invasor Cristóvão Colombo, identificado em Los perros del paraíso como uma espécie de anfíbio:

\begin{abstract}
Fue entonces cuando pudo enterarse del secreto que hasta entonces sólo conocía Susana Fontanarrosa y que Colón había ocultado siempre tras la densa malla de sus calcetines: entre el segundo y tercer dedo de cada pie había una membranita unitiva, como la de los patos y otros animales de ambiente acuático-terrestre. El Almirante era palmípedo y - ya no cabían dudas preferencialmente anfibio. (POSSE, 1989, p. 222).
\end{abstract}

Voltando ao cerne da questão, no contexto crítico dos estudos literários, ainda que o modelo scottiano (LUKÁCS, 1966) tenha sedimentado grande parte dos eixos para o desenvolvimento desse tipo de ficção, é também certo afirmar que tal modalidade narrativa ganhou fôlego deste lado do Atlântico desde Xicoténcatl, obra publicada em 1826 e de autoria não identificada. O crítico Alexis Márquez Rodríguez ratifica a dimensão do primeiro romance histórico publicado na América hispana, ponderando que

\begin{abstract}
[e]sta primera novela histórica hispanoamericana nace ya dentro de una nueva concepción del género, que rompe con el esquema que de éste había impuesto Walter Scott: el elemento histórico aparecía en las obras del autor británico como una especie de telón de fondo que daba carácter y ambientación al argumento de la novela, argumento que, sin embargo, era puramente ficticio, si bien perfectamente identificado con la época en la que, supuestamente, transcurre la acción. En el esquema ensayado por el anónimo autor de Jicoténcal se invierten los términos, y lo histórico pasa a un primer plano mientras la ficción se ocupa de los elementos secundarios. Quizá alguien pudiera preguntarse qué es lo novelesco en esta novela, cuando la novela, tradicionalmente, ha sido definida como "narración ficticia". (MÁRQUEZ RODRÍGUEZ, s. n.).
\end{abstract}

Em regiões austrais, a relação entre ficção e história também demonstrou fertilidade. Desde o início, a Argentina, tal como em grande parte dos demais países do continente, revelou-se palco de diferentes irrupções coletivas responsáveis por engendrar um novo espaço 
capaz de pintar, com as cores românticas finisseculares, a identidade de uma nação livre do colonizador (SOMMER, 2004). Talvez, aspirando certo espírito romântico, a crítica literária e professora argentina Mercedes Giuffré, em seu ensaio En busca de uma identidad (La Novela Histórica en Argentina), publicado em 2004, tenha se convencido de que o romance histórico argentino enquanto modalidade narrativa fosse capaz de assegurar uma então "personalidade argentina" (GIUFFRÉ, 2004, p. 11). Tal como discutido anteriormente (CERDEIRA, 2019), a ideia de uma personalidade específica é questionável, sobretudo se a tratamos de forma monológica, afinal, a qual "personalidade argentina" estaríamos realmente nos referindo? Seja como for, a conjuração se revela, nesta instância, ilustrativa, ao menos para retratar o quanto a modalidade narrativa encontrou em solo austral grande profusão.

A afirmativa pode ser corroborada a partir do cotejo de Noé Jitrik em seu ensaio “Historia e imaginación literaria: las posibilidades de un género" (1995), atento ao fato de que “[...] aunque no se haya producido espontáneamente en América Latina, ese producto histórico de la cultura europea se implantó tan rápidamente y con tanta perdurabilidad en el continente." (JITRIK, 1995, p. 20).

Ao delinear a tradição para friccionar ficção e história na Argentina, é inevitável ampliar o raciocínio e versar sobre alguns dos textos e nomes seminais para a constituição dos discursos oficiais no país. Dessa forma, poderíamos rapidamente aludir às obras Facundo (1845), de Domingo Faustino Sarmiento; Amalia (1851), de José Mármol; as reflexões a partir de trocas epistolares dos irmãos Lucio e Eduarda Mansilla; a narrativa curta El matadero (1838-1840), de autoria de Esteban Echeverría, intelectual reconhecido como uma espécie de fundador do trabalho do Romantismo na América Latina a partir do ano de 1830 (JITRIK, 1995) e representante máximo da geração de 1837; as inúmeras obras e estudos críticos de Manuel Gálvez ligados ao romance histórico; ou, claro, a obra-chave La novia del hereje (1854), de Vicente Fidel López, considerada pela grande maioria da fortuna crítica argentina o primeiro romance histórico do país.

Interessada em fundamentar um panorama da construção da ficção histórica na Argentina, a crítica Corina Mathieu referenda:

La ficción histórica en la Argentina goza de una tradición bien establecida cuyo origen se remonta al siglo XIX y coincide con la organización nacional. La trascendencia que el romanticismo otorgó al individuo y a la libertad política, fundamento de la creación artística, en conjunción con los acontecimientos políticos que se dieron en el Río de la Plata durante este período, contribuyeron a la rica y 
heterogénea producción literaria de la primera etapa independiente del país. (MATHIEU, 2004, p. 29).

Falar em "personalidade argentina", de certo modo, justifica-se não por uma particularidade, mas como um artifício retórico para salientar a pujante e contínua produção do século XIX até a grande presença nas últimas três décadas -, notoriamente percebida não somente a partir das publicações que advêm do centro, ou seja, de Buenos Aires, mas que inundam as prateleiras a partir da presença de leitores de diversas províncias, como o caso de Córdoba a partir de escritores como Reyna Carranza, Marta Mercader e Cristina Bajo, escritor, aliás, responsável por desencadear a chamada "oleada bajo" (CERDEIRA, 2019, p. 241, grifos do autor), um movimento não apenas de proliferação de novos nomes interessados a querer interseccionar ficção e história, mas, efetivamente, de aquecimento e descentralização do próprio mercado editorial.

O fato curioso é que, ainda que o país demarque um contexto produtivo para o desenvolvimento do romance histórico, a terminologia suscitada primeiramente por Fernando Aínsa (1991, 1996) e legitimada por Seymour Menton (1993) não parece ser a predominante, ao menos em termos quantitativos e qualitativos (CERDEIRA, 2019). Cabe, por isso, um aparte sobre a terminologia "novo romance histórico". Ao longo da tese Argentum Córdoba (CERDEIRA, 2019), a discussão sobre a relativização do termo novo romance histórico como uma constante eminente para pensar a produção argentina já fora relativizada e criticada:

\footnotetext{
[...] no caso argentino, o imaginativo novo romance histórico não parece ser exatamente o mais praticado, contrariando o que o crítico estado-unidense poderia prever como uma tendência a ser disseminada e levada ao máximo depois do afã causado pelos romancistas do boom na década de setenta do século XX. Minha afirmação é fruto de uma leitura pautada nos próprios dados apresentados no ensaio La nueva novela histórica de la América Latina, 1979-1992. Ora, basta voltar ao que está registrado de saída no Prepéndice do trabalho, quando Menton institui a lista do que seriam as obras que, entre 1979 e 1992, justificaria a perspectiva de se apregoar o aditivo novo para a modalidade do romance histórico. Das 56 obras apontadas como representantes do novo romance histórico, apenas 11 são narrativas de escritores argentinos, sendo que o cordobês Abel Posse seria responsável por três dessas produções, os romances Daimón (1978), Los perros del paraíso (1983) e, finalmente, El largo atardecer del caminante (1992). (CERDEIRA, 2019, p. 206).
}

Como se sabe, os romancistas históricos latino-americanos buscaram mudar a escrita construída por indivíduos que pertencem ao centro da sociedade, delineando o quanto "[...] a nova função historiografia e do romance histórico consiste em explorar as descontinuidades e interseções desconsideradas pelo projeto da modernidade [...]" (ESTEVES, 2017, p. 179). 
Além disso, as perspectivas oferecidas pelas diegeses “[...] evidenciam também a experiência das margens, das vozes silenciadas, das comunidades e dos sujeitos propositalmente negligenciados nos relatos oficiais." (FLECK, 2017. p. 57). Sem nos alongarmos aos tensionamentos dados às taxonomias críticas, o que nos interessa neste artigo é ponderar como a menção à Trilogia do Descobrimento como uma personificação para a chancela da designação de novo romance histórico, ecoa o quanto o projeto ficcional de Posse ganhou atenção da crítica especializada responsável pela formatação do chamado cânone literário. $\mathrm{O}$ interesse de Menton ao projeto ficcional de Posse não é uma surpresa, aliás, já que o próprio crítico se referiu em um evento acadêmico ao escritor argentino e ao último romance da trilogia como "[...] uno de los grandes autores hispanoamericanos, tal vez el novelista más importante del "posboom"." (MENTON, s. n.).

De qualquer maneira, mesmo que seja possível, a qualificação de "novo romance histórico" parece problemática, uma vez que as seis balizas aludidas por Menton para atestar o adjetivo atrelado ao romance histórico parecem ser reduzidos ao, no máximo, dois elementos (WEINHARDT, 2011). Da mesma forma que ocorre com as produções ficcionais de Pedro Orgambide e César Aira, os romances de Abel Posse, em nossa leitura, parecem oferecer possibilidades críticas mais produtivas quando analisados sob a égide de flexibilizar e inovar as formas de consagrar os encontros entre ficção e histórica (CERDEIRA, 2019). Em uma entrevista com a já mencionada crítica argentina Mercedes Giuffré, reforça-se mais uma vez a inviabilidade de se frisar o termo "novo romance histórico" no campo literário argentino:

\begin{abstract}
MG: Yo veo que en la Argentina, justamente, eso [referindo-se a uma produção mais ligada ao que Menton e Aínsa lêem como novo romance histórico] no cuajó tanto. Acá lo que abundó en la época en la que él escribe ese ensayo es la novela histórica que trabaja con los documentos historiográficos y que trata de trabajar, como hago yo, en los olvidos de ese discurso. Pero no está cuestionando la veracidad de ese discurso, sino lo está mirando sin ingenuidad, sabiendo que todo discurso es manipulable. No está atacándolo, tampoco negándolo. (GIUFFRÉ apud CERDEIRA, 2019, p. 207).
\end{abstract}

Diante de um rápido panorama a respeito da tradição de se fazer ficção a partir das múltiplas interseções com o discurso histórico na Argentina, passa a ser possível dar destaque ao projeto literário de Abel Posse e, pontualmente, às transformações personificadas ao longo dos três romances que compõem a Trilogia do Descobrimento. 
2 Formas de (re)contar a história: a poética do descobrimento transformada na trilogia de Abel Posse

O ano de 1992 pode ser recuperado como um interessante marco temporal, sobretudo quando a seara circunscreve as perspectivas histórica e ficcional da América Hispana. Mais do que simplesmente sedimentar o abstrato - afinal, como sabemos, uma data nada mais é do que a tentativa de racionalizar, ao lado de um dado espaço, aquilo que Mikhail Bakthin (1986) intitulará como um cronotopo -, esse marco histórico foi o responsável por resgatar simbolicamente os cinco séculos de invasão promovidos pelo agente europeu no continente americano. Localizado por Seymour Menton (1993) como uma referência para a (re)visão da chegada de Cristovão Colombo na América, o ano também emoldura a publicação de $E l$ atardecer del caminante, última obra que compõe o corpus ficcional selecionado por este artigo.

Composta ainda, tal como anunciado no início, por Daimón (1978) e Los perros del paraíso (1983), a Trilogia do Descobrimento foi responsável pelo reconhecimento internacional do escritor Abel Posse. Quatro anos depois da publicação oficial do primeiro romance da série, o cordobês foi selecionado ao Prêmio Rómulo Gallegos. A premiação foi conquistada, no entanto, cinco anos depois, a partir da escrita de Los perros del paraíso. No mesmo ano do lançamento do último romance da trilogia, isto é, em 1992, El largo atardecer del caminante recebeu o Prêmio Internacional Extremadura-América. A inserção de Posse em um dado campo intelectual e, fundamentalmente, as suas escolhas para alicerçar as diegeses justificam o porquê de teóricos da literatura o localizarem como um representante da nova narrativa argentina (em castelhano, nueva narrativa argentina). Segundo a crítica literária Elsa Drucaroff, a delimitação diz respeito à produção de autores que nasceram após a década de 60, mas que começaram a publicar efetivamente trinta anos depois, ou seja, na década de 90. Com projetos e procedimentos narrativos não necessariamente análogos, além de Abel Posse, poderiam ser circunscritos à geração escritores como Martín Kohan, Gabriela Cabezón Cámara etc. Sob o olhar da crítica de Drucaroff, há ainda uma relação com outra geração, que, segundo ela, não deve ser tomada como uma sinonímia, sendo essa sintonizada a partir da atribuição narrativa de las generaciones de postdictadura, que, tal como o nome já adianta, tem um recorte mais específico na preocupação de plasmar ficcionalmente os traumas sofridos pelo período de chumbo (DRUCAROFF, 2011). 
Vale, agora, apontar certos caminhos tomados por Posse para construir a sua chamada Trilogia do Descobrimento. Apesar de mencionarmos as três obras nesse artigo dar-se-á foco ao terceiro romance, tendo em vista que se trata de um artigo introdutório, sendo assim, posteriormente, serão analisados os outros dois romances também.

O primeiro romance, Daimón (1978), apresenta uma releitura sobre a conquista das novas terras. A narrativa apresenta o viés do colonizado, ou seja, quem narra a história é uma personagem que não figura no discurso histórico oficial. Em nossa leitura, parece haver um interesse mais franco em desconstruir a versão apresentada pelo discurso histórico. A obra apresenta linguagem irônica, o que oferece ao leitor uma leitura divertida. A partir disso, essa primeira obra possui características do novo romance histórico, ao menos se seguirmos os parâmetros apresentados por Seymour Menton (1993).

A segunda obra da trilogia, intitulada Los perros del paraíso (1983), ficcionaliza algumas personagens da história oficial, tais como Cristóvão Colombo e os Reis Católicos. A narrativa recorre à paródia, à intertextualidade, ao humor e, também, à distorção dos fatos apresentados pela historiografia. Vale ressaltar que essa obra é uma mescla entre intertextualidade e metaficção. Sendo assim, a partir de todos esses elementos que o autor utilizou no decorrer da escrita, nota-se que o relato é um dos exemplares de novo romance histórico latino-americano que eficazmente se vale dos recursos metaficcionais para imprimir criticidade ao discurso ficcional que relê o passado.

No terceiro romance, El largo atardecer del caminante, Posse constrói um foco narrativo no qual as lembranças da personagem Alvar Núñez Cabeza de Vaca dão conta de todo o andamento. O narrador autodiegético é também a protagonista do romance, visto que ele narra as lembranças que tem sobre o período em que participou do descobrimento. Novamente, o autor apresenta uma versão diferente do descobrimento, porém, dessa vez, ele recorre a fatos apresentados pela história oficial, além da ficção. A diegese é constituída de duas partes: o que ocorreu próximo ao momento da narração; e, ainda, os acontecimentos que ocorreram nos períodos passados da narrativa. Apesar de o autor utilizar os tempos verbais pretérito e presente, ambas as partes são formadas por discursos lineares.

Pela questão dessa obra ser formada por elementos factuais e ficcionais, ou seja, apresenta períodos de distorção da história do modelo histórico consagrado, com a presença de uma linguagem amena - sem grandes soluções sintáticas ou lexicais -, o que permite que o leitor tenha uma leitura majoritariamente fluída. Ainda assim, são identificáveis períodos com 
intertextualidade, paródia e ironia, o que demanda um pouco mais de atenção do leitor. O fato de não apelar para a desconstrução ou para o questionamento do registro oficial, fortalecendo uma nuance distinta de diálogo entre ficção e histórica, faz que o último romance da trilogia ofereça uma franca relação com o que o crítico literário e professor brasileiro Gilmei Francisco Fleck intitula enquanto romance histórico contemporâneo de mediação (FLECK, 2017). Entre a fase tradicional do romance histórico - intitulado por parte da fortuna crítica como romance histórico romântico ou romance histórico scottiano/lukacsiano - e o novo romance histórico, ganharia, então, a fase denominada como mediativa, surgida em meados do século XX. Tratar-se-ia, segundo o professor Fleck, de obras que dão espaço aos indivíduos que foram excluídos, deixados de lado e esquecidos na versão da história contada pela historiografia do modelo oficial. Tal modalidade de escrita possui as seguintes características:

1- Uma releitura crítica verossímil do passado; 2- Uma narrativa linear do evento histórico recriado; 3- Foco narrativo geralmente centralizado e ex-cêntrico; 4Emprego de uma linguagem amena, fluída e coloquial; 5- Emprego de estratégias escriturais bakhtinianas; 6- Presença de recursos metaficcionais. (FLECK, 2017, p. $109-111)$.

O romance histórico contemporâneo de mediação é, segundo Fleck, a modalidade mais utilizada na escrita atual, tendo em vista que as características presentes nesses romances, sobre o passado histórico, deixam a leitura mais leve e prazenteira:

\footnotetext{
Os romances históricos contemporâneos de mediação, justamente pela redução da complexidade na linguagem e na estrutura, atingem um público leitor bastante amplo, uma vez que podem ser compreendidos por jovens leitores ainda em formação, ou mesmo por aqueles leitores adultos que, ao longo de seu processo de escolarização, não tiveram a oportunidade de se tornar leitores críticos, considerando-se essa etapa mais avançado do processo de formação de leitores que, em nossa realidade escolar, poucas vezes chega acontecer. (FLECK, 2017, p. 106).
}

O crítico ainda enfatiza que o romance histórico contemporâneo de mediação não se fixa em heróis apresentados pela historiografia, como ocorre com o novo romance histórico. Antes da desconstrução do viés apresentado pela história tradicional, busca-se dar voz aos que foram deixados de lado pela historiografia. Para justificar a ideia de mediação, concentremonos a seguir em alguns dos detalhes pertencentes à diegese do último romance da trilogia.

O narrador está situado na Espanha, enquanto recorda a sua aventura de naufrágio e cativeiro durante o descobrimento. Vale destacar que o tempo presente do narrador é na 
península, enquanto que o tempo passado são suas lembranças de mais de 10 anos em que viveu no meio de nativos americanos. Mesmo que, na diegese, esses tempos sejam marcados, não ocorre a sobreposição, ou seja, no presente da narrativa, a protagonista - Álvar Núñez Cabeza de Vaca - encontra-se na Espanha à espera de um julgamento e utiliza de lembranças para mencionar seu passado.

A obra inicia com a ida da personagem até a biblioteca da Torre de Fradique, em busca de alguns mapas, para localizar as terras pelas quais passou durante o período do descobrimento. Nessa biblioteca, Cabeza de Vaca conhece a personagem Lucinda, jovem que já conhecia a crônica Naufragios y comentários (1542), escrita pelo conquistador, disposto a descrever alguns dos fatos sobre as viagens que realizou nos tempos passados. Diante disso, Lucinda lhe entrega uma folha de papel para que ele possa continuar sua história. A partir de tal disparador ficcional, a personagem de gênese histórica volta a relatar as aventuras que vivenciou na América, utilizando-se de recursos mnemônicos.

A personagem inicia as suas recordações descrevendo o ambiente em que vivia:

\footnotetext{
Ahora recuerdo de la casa en la finca de Extremura. La mañana fresca y diamantina de invierno. El aire leviano, el cielo como un azul de taza china. Creo ver el perfil de la madre, pero en realidad no lo recuerdo (POSSE, 1992, p.13).
}

Nota-se que a personagem recorda com detalhes do ambiente em que vivia com sua mãe, porém, não consegue relembrar da imagem de sua progenitora. No início da obra, é ressaltado o processo de escolha de seu nome. Descobre-se, pois, que Alvar Núñez Cabeza de Vaca foi escolhido por sua mãe, tendo como referência um herói. Desde pequeno na localidade em que moravam, mãe e filho tinham contato com Deus:

\footnotetext{
Nuestro dios era el Viejo olímpico y pagano. El Dios del Génesis. Admirable y minucioso creador. Adorador del sinsentido y del absurdo. Más preocupado por los infinitos espacios del cosmos que las mimiedades de esta Tierra, un planeta sin luz própria (POSSE, 1992, p.15).
}

No decorrer da obra, Cabeza de Vaca relembra o seu enlace com a indígena Amaría. Ele descreve que seu envolvimento com ela foi de grande amor e respeito, porém, jamais havia mencionado tal relação para ninguém por ser orgulhoso e também por não envergonhar 
sua família: “¿Cómo decirles de vida marital con una índia?” (POSSE, 1992, p.88). Entendese, ao menos pela narrativa, que Cabeza de Vaca permaneceu calado sua vida toda.

Com a índia, o espanhol teve seus filhos Amadís e Nube. O narrador-personagem ressalta que aprendeu várias atividades com os indígenas, tendo em vista que tinha total respeito pelo povo. Em uma de suas lembranças de seus filhos, a personagem relata: "Recordé a Amadís corriendo por el prado del valle chorruco, su velocidad de gamo, su carita siempre sucia de barro y hasta la quemadura de su hombro (POSSE, 1992, p. 90). Cabeza de Vaca demonstra incredulidade quanto à natureza dos indígenas, já que as mulheres trabalhavam muito e tinham pouco tempo para se divertir. Quando tinham filhos, o maior tempo delas era destinado à amamentação.

Outra personagem que aparece no decorrer da obra é "El viejo Oviedo", alusão a outra figura empírica, isto é, que realmente existiu no plano histórico. Cabeza de Vaca relata que Oviedo chegou a Sevilla para questionar sobre o que realmente havia ocorrido em suas viagens no período do descobrimento. Essa personagem trata-se de González Fernando de Oviedo, considerado como o dono da história no contexto espanhol:

Es evidente que don Gonzalo Fernández de Oviedo está convencido de que la Conquista y el Descubrimiento existen sólo en la medida en que él supo recuperar, organizar y relatar los hechos. Es el dueño de lo que suele llamar ahora la historia. (POSSE, 1992, p.26).

Nesse momento do enredo, nota-se que Posse faz uma crítica sobre a versão do descobrimento apresentada pela história oficial. Cabeza de Vaca e Oviedo discutem. Ocorre um debate entre os dois e Oviedo questiona as lembranças de Cabeza de Vaca, colocando em dúvida se essas são verdadeiras ou não. Diante desse embate das personagens, vê-se na obra uma característica do romance histórico contemporâneo de mediação: trata-se de uma crítica verossímil do passado, ou seja, Cabeza de Vaca questiona que somente a versão apresentada por Oviedo seja verdadeira. Merece destaque um fragmento no qual o narrador-personagem Cabeza de Vaca utiliza-se da ironia para dizer que Oviedo é o conquistador dos conquistadores:

Oviedo, que escribe catorce horas por día, será el conquistador de los conquistadores, el depósito de la verdad. El corral de hechos y personas. Hará con la pluma mucho más de lo que efectivamente hicimos nosotros con la espada. 
Curioso destino. Pero Jehová mismo no sería Jehová si los judíos no lo hubiesen encerrado en un libro. (POSSE, 1992, p. 29).

A partir do excerto anterior, verifica-se a presença de outra característica do romance histórico contemporâneo de mediação, os recursos bakhtinianos, sobretudo, a paródia e a ironia. No meio da conversa em que Cabeza de Vaca protagoniza com Lucinda, o narrador relata que, em uma de suas viagens, um menino chamado Sandoval colocou um grilo escondido em seu navio, porém, dias depois, foram surpreendidos pelo cantar do grilo e um dos viajantes alertou que se o grilo estava cantando era porque as terras estavam perto. Lê-se, assim, a ironia quando Cabeza de Vaca diz "En cambio un grillo, un simple grillo, puede salvar una flota, le digo a Lucinda que me mira sorprendida." (POSSE, 1992, p. 60). Depois de encontrarem as terras, eles festejam com o grilo, servem vinho e colocam uma coroa nele para festejar a descoberta. Essa é mais uma característica do romance histórico contemporâneo de mediação que aparece na obra. Vale destacar que, ao ouvir esse relato, a personagem Lucinda deu gargalhadas e se divertiu.

Mais uma vez, vale ressaltar que o tempo em que a narrativa acontece é linear, iniciando com a personagem Cabeza de Vaca na Espanha, à espera de seu julgamento, até o momento em que ele encontra seu filho entre os cativos; nessa espera, figuram as lembranças do que vivenciou durante os naufrágios.

De maneira geral, nos romances da Trilogia do Descobrimento, algumas informações históricas estão presentes, porém, há várias informações que são descritas e que não podem ser acatadas como "verdadeiras". Diante de tal impasse, parece-nos plausível ponderar que a viabilidade de tomar o preceito de que "história é ciência e literatura é arte" (2017, p. 27). A partir disso, pode-se entender que essa releitura da história sobre o descobrimento é obra de arte produzida por Posse, uma vez que ele saiu do viés da ciência dominada por um discurso consagrado e produziu um novo caminho.

Em uma de suas reflexões, Fleck salienta que "[...] a tarefa de mostrar a verdade do acontecido pela escrita da história é, de qualquer modo, mediada pela construção de um discurso no qual atua um narrador que, subordinado às ações do sujeito que o elabora como entre narrativo, faz recortes" (FLECK, 2017, p. 29). No projeto ficcional de Posse e, sobretudo, na obra El largo atardecer del caminante, quem tem domínio no discurso para mostrar a "verdade" dos fatos é a personagem Alvar Núñez Cabeza de Vaca; ela é um 
narrador autodiegético, demarcada por um tempo presente no qual está na Espanha esperando um julgamento e, ao mesmo tempo, recorda sua aventura de naufrágio e cativeiro no período do descobrimento. Sendo assim, os fatos são narrados a partir das lembranças trazidas à memória por ele no decorrer da história.

Sabe-se que a segunda fase do romance histórico, para grande parte da fortuna crítica da modalidade narrativa, é marcada pelo desconstrucionismo. Esse discurso não descreve a história edificando os heróis da historiografia, fazendo com que a ficção dê certa prevalência para contradizer os discursos construídos pela perspectiva eurofalocêntrica, ou seja, os discursos vindos de documentos oficiais que foram escritos pela corte. Diferentemente dos outros dois romances da Trilogia do Descobrimento, a primeira obra da trilogia selecionada para esse artigo, Daimón (1978), consagra um alicerce ficcional mais concernente ao tom desconstrucionista relatado, apresentando uma linguagem repleta de paradoxos, ironias, anacronismos e simultaneidade (ARACIL VARÓN, s. n.). Não à toa, são exatamente esses recursos linguísticos os responsáveis por causar a ruptura com o discurso histórico. Ao contrário do que ocorre no segundo romance da trilogia, ao resgatar a figura histórica de Lope de Aguirre, Posse marcara uma opção de escrita para desconstruir os acontecimentos do passado e, via ficção, propor uma releitura do que fora consagrado. Certo tom mais questionador do escritor argentino no início da série foi também detectado pela pesquisadora Mayra Borbón, responsável por afiançar a seguinte proposição:

La predilección del escritor Abel Posse por el conquistador Lope de Aguirre evidencia una filiación a cierto discurso, el de la rebelión, con el que su personaje nos ubica en el singular episodio de la Conquista de América simbolizada por el alzamiento de los marañones, pero bajo una nueva perspectiva que difiere de la Historia oficial que sataniza al protagonista de la Jornada de Omagua y El Dorado. (BORBÓN, 2011, p. 65).

Vale lembrar que o marco inicial da segunda fase ocorreu justamente na América Hispânica e os autores das obras escritas nessa fase buscaram descrever o ponto de vista do colonizado e o explorado, ou seja, o foco das obras que pertencem a essa fase não está mais naqueles que colonizaram as populações da América Latina. O crítico Gilmei Francisco Fleck relembra que, nessa fase protagonizada pelo romance histórico, os indivíduos passam a refletir sobre as inúmeras possibilidades e perspectivas dos fatos que ocorreram no passado. Dessa forma, essa leitura apresentada por esse novo modelo é crítica, tendo em vista que possui um foco narrativo centrado em “[...] mulheres, negros, nativos, europeus subalternos, 
degredados, fugitivos, portadores de necessidades especiais, rebeldes, anti-heróis.” (2017, p. 105).

Não é segredo que o romance histórico agrada, na maioria das vezes, o homem contemporâneo, pois além de qualquer outra forma de escrita, apresenta uma linguagem com mesclas, ou seja, fatos históricos e argumentos ficcionais. É necessário ter o equilíbrio dos argumentos no decorrer da escrita. Os escritores comprovam, portanto, não apresentar uma única alternativa dos fatos, podendo atestar distintas versões que podem, por sua vez, serem acatadas como legítimas. Nota-se, novamente, que a literatura, como todo discurso, mantémse em transformação. Em cada nova proposição na literatura são atribuídas ao romance histórico características renovadoras e são retiradas outras, tendo em vista que a escrita vai abrangendo outros campos. Deve-se observar que, na atualidade, não há mais um modelo único de escrita híbrida de história e ficção (AÍNSA, (1991) - como foi regra no início das escritas do gênero romance histórico -, pois os escritores têm, hoje, maior liberdade de escrever textos utilizando os recursos que mais lhes parecem interessantes para propor distintas vias de releituras do passado pela ficção.

Ao cotejar os romances de Abel Posse como a Trilogia do Descobrimento, passa a ser mais plausível ler a obra El largo atardecer del caminante como integrante da terceira fase, isto é, um típico romance histórico contemporâneo de mediação, pois essa nova modalidade apresenta uma perspectiva que relaciona os argumentos da fase acrítica e da fase crítica.

Nota-se que o terceiro romance da trilogia do Descobrimento se encaixa nessa modalidade mediativa por alguns motivos: a) Nele se relê o passado de forma crítica; b) porque o tempo da narrativa privilegia a linearidade, com inserção simples de analepses, tornando o processo de leitura mais ameno, com o uso de uma linguagem acessível com certa ironia sutil; c) porque nele não há indícios de experimentalismos linguísticos e formais, aspectos altamente explorados nas duas obras antecedentes; d) porque não há nele a intenção de "desconstruir" nenhum grande personagem da história hegemônica, nem mesmo seu discurso, pelo emprego de recursos como a carnavalização e o grotesco, ambas frequentes nos romances antecedentes; e) pelo foco narrativo escolhido. Em sua diegese, a personagem Alvar Núñez Cabeza de Vaca tem espaço para narrar tudo o que vivenciou durante o descobrimento, apontando fatos que nunca foram citados pela história oficial. Ocorre, então, no último romance a história "vista de baixo". Segundo o historiador Jim Sharpe, no ensaio "A história vista de baixo", "[...] a história tem sido encarada, desde os tempos clássicos 
como um relato dos feitos grandes" (SHARPE, 1992, p. 40), partindo desse ponto, a grande maioria das histórias prioriza detalhar os acontecimentos que reforçam o poder da elite. Mais precisamente, enfatizar a versão dos fatos apresentados por uma dada comunidade de reconhecimento. Ao eleger uma personagem histórica central para subsidiar o foco narrativo do último romance da trilogia, Posse valoriza a mediação entre ficção e história.

Ao longo de toda a trilogia, os romances possuem a temática voltada para o descobrimento, na qual o fato histórico é reconstruído pela obra ficcional. As narrativas descrevem o período do descobrimento a partir do olhar das personagens protagonistas, parodiando textos e registros da história oficial. Tais versões, embora pertencentes - segundo nossa leitura - a segunda (críticaldesconstrucionista) e a terceira (mediativa) fases das escritas híbridas de história e ficção - revelam-se releituras críticas, cada qual a sua medida.

\section{Algumas considerações: não se trata de concluir, apenas de começar a narrar}

Desde o lançamento do estudo crítico sobre como o discurso ficcional passa a ser interseccionado por signos da história não apenas como pano-de-fundo, mas como um elemento de desenvolvimento de toda a diegese, o húngaro Georg Lukács já alertava a respeito do caráter mutante desse tipo específico de narrativa. O então romance histórico consagrado no afã romântico do século XIX ganhou asas e, na América, acabou protagonizando tal espírito de transformação com o chamado novo romance histórico (AÍNSA, 1991, 1996; MENTON, 1993, 1999), o romance do pós-boom, a metaficção historiográfica (HUTCHEON, 1991), o romance histórico contemporâneo de mediação (FLECK, 2017), entre outras nomenclaturas.

Diante de toda essa profusão, o presente artigo buscou apresentar uma leitura de aproximação de três romances do argentino Abel Posse - Daimón (1978), Los perros del paraíso (1983) e El largo atardecer del caminante (1992) -, que, juntos, compõem uma trilogia interessada em versar a respeito do descobrimento americano. Como anunciado desde o início, tratou-se de um esforço inicial e que, portanto, será expandido em um trabalho crítico de maior envergadura, demonstrando como o projeto ficcional de Posse parece oscilar de um caráter mais desconstrucionista até um ponto em que a ficção passa a estar mais a serviço de uma mediação para (re)pensar o que havia sido oficializado.

Entre ficção e história, os romances de Abel Posse oferecem a oportunidade de pensar o descobrimento não como algo benevolente por parte daquele que colonizou, mas como 
inspiração para dar voz àqueles que foram invadidos. Em linhas gerais, o texto buscou apresentar um viés reflexivo sobre os acontecimentos do passado histórico; essa reflexão trata-se em pensar que os fatos apresentados pela história oficial não podem ser aceitos como a única "verdade" (se é que realmente exista alguma).

\section{Referências}

AÍNSA, Fernando. La nueva novela histórica latinoamericana. Plural, n. 240, p. 82-85, 1991.

AÍNSA, Fernando. Nueva novela histórica y relativización del saber historiográfico. Casa de las Américas, n. 202, enero-marzo, 1996.

ARACIL VARÓN, Beatriz. Daimón de Abel Posse: hacia una nueva crónica del descubrimiento. Disponível em: <https://www.researchgate.net/publication/39506276_Daimon_de_Abel_Posse_hacia_una_nu eva_cronica_de_America>. Acesso em 03 jan. 2020.

BAKHTIN, Mikhail. Problemas literários y estéticos. La Habana: Editorial Arte y Literatura, 1986.

BORBÓN, MAYRA. La reconstrucción de la historia americana en Daimón de Abel Posse. Revista TRIM, n. 3, 2011, p. 63-74. Disponível em: <https://dialnet.unirioja.es/descarga/articulo/4791786.pdf>. Acesso em 04 jan. 2020.

BOURDIEU, Pierre. El campo literario. Prerrequisitos críticos y principios de método, Critérios, La Habana, n. 25-28, enero 1989-diciembre 1990, p. 20-42. Trad. Desiderio Navarro. Disponível em: <http://educacion.deacmusac.es/practicaslegitimadoras/files/2010/05/bourdieucampo.pdf.>. Acesso em: 17 ago. 2019.

BOURDIEU, Pierre. Campo de poder, campo intelectual. Buenos Aires: Editorial Montressor, 2002.

CARPENTIER, Alejo. La novela latinoamericana en vísperas de un nuevo siglo. In: CARPENTIER, Alejo; RODRÍGUEZ MONEGAL, Emir; CHIAMPI, Irlemar et al. Historia y Ficción en la narrativa hispanoamericana. Coloquio de Yale. Compilación y Prólogo de Roberto González Echevarría. Caracas: Monte Ávila Editores, 1984. p. 19-48.

CERDEIRA, Phelipe de Lima. Argentum Córdoba: diálogos, fissuras e soslaios entre ficção e história sob as miradas de Cristina Bajo, Andrés Rivera e María Teresa Andruetto. Tese de Doutorado, Programa de Pós-graduação em Letras, Universidade Federal do Paraná, 2019, Curitiba. 569 p.

DA CUNHA, Gloria (Ed.). La narrativa histórica de escritoras latinoamericanas. Buenos Aires: Corregidor, 2004. 
DRUCAROFF, Elsa. Prisioneros de la torre. Buenos Aires: Emecé, 2011.

ESTEVES, Antonio Roberto. História e memória. In: GONZÁLEZ, Elena C. Palmero; COSER, Stelamaris. Em torno da memória: conceitos e relações. Porto Alegre: Editorial Letra1, 2017, p. 171-180.

FLECK, Gilmei Francisco. O romance histórico contemporâneo de mediação: entre a tradição e o desconstrucionismo - leituras da história pela ficção: Curitiba: CRV, 2017.

FLECK, Gilmei Francisco. O romance, leituras da história: a saga de Cristóvão Colombo em terras americanas. 2008. 333 f. Tese (Doutorado em Letras - Literatura Comparada) Universidade Estadual Paulista Julio de Mesquita Filho, Assis, 2008.

GIUFFRÉ, Mercedes. Entrevista realizada para a tese Argentum Córdoba. [Entrevista cedida a] Phelipe de Lima Cerdeira. Buenos Aires, 2017.

GIUFFRÉ, Mercedes. En busca de una identidad (La Novela Histórica en Argentina). Buenos Aires: Ediciones del Siglo, 2004.

HUTCHEON, Linda. Poética do pós-modernismo: história, teoria, ficção. Trad. Ricardo Cruz. Rio de Janeiro: Editora Imago, 1991.

JITRIK, Noé. Historia e Imaginación Literaria, las posibilidades de un género. Buenos Aires: Editorial Biblos, 1995.

LUKÁCS, Georg. La novela histórica. Trad. Jasmin Reuter. México D.F.: Ediciones Era, 1966.

MÁRQUEZ RODRÍGUEZ, Alexis. In: SÁINZ DE MEDRANO, Luis. La narrativa de Abel Posse: Historia y ficción. Biblioteca Virtual Miguel de Cervantes. Disponível em: $<$ http://www.cervantesvirtual.com/obra-visor/la-narrativa-de-abel-posse--historia-yficcion/html/67e5f68d-84e8-44cc-838e-373ea189496d_2.html>. Acesso em 10 jan. 2020.

MATHIEU, Corina. Argentina. In: DA CUNHA, Gloria (Ed.). La narrativa histórica de escritoras latinoamericanas. Buenos Aires: Corregidor, 2004.

MENTON, Seymour. La nueva novela histórica de la América Latina: 1979-1992. México: Fondo de Cultura Económica, 1993.

MENTON, Seymour. Las últimas noticias de la nueva novela histórica. In: ALBA DE AMÉRICA. Revista Literaria: reescritura de la historia en la literatura del mundo hispánico. XV Simposio Internacional de Literatura, San Carlos de Bariloche, Río Negro, Argentina, v. 17, n. 32, marzo 1999, p. 61-68.

MENTON, Seymour. In: SÁINZ DE MEDRANO, Luis. La narrativa de Abel Posse: Historia y ficción. Biblioteca Virtual Miguel de Cervantes. Disponível em: 
<http://www.cervantesvirtual.com/obra-visor/la-narrativa-de-abel-posse--historia-yficcion/html/67e5f68d-84e8-44cc-838e-373ea189496d_2.html>. Acesso em 10 jan. 2020.

MIGNOLO, Walter. Historias locales, diseños globales. Colonialidad, conocimientos subalternos y pensamiento fronterizo. Buenos Aires: Akal Ediciones, 2003.

PONS, María Cristina. El secreto de la historia y el regreso de la novela histórica. In: DRUCAROFF, Elsa (Directora). Historia crítica de la literatura argentina. La narración gana la partida. v. 11. Buenos Aires: Emecé, 2000. p. 97-116.

POSSE, Abel. Daimón. Barcelona: Argos Vergara, 1981.

POSSE, Abel. Los perros del paraíso. Ciudad de la Habana: Editorial Arte y Literatura, 1989.

POSSE, Abel. El largo atardecer del caminante. Buenos Aires: Emecé Editores, 1992.

SÁINZ DE MEDRANO, Luis. La narrativa de Abel Posse: Historia y ficción. Biblioteca Virtual Miguel de Cervantes. Disponível em: <http://www.cervantesvirtual.com/obra-visor/lanarrativa-de-abel-posse--historia-y-ficcion/html/67e5f68d-84e8-44cc-838e-

373ea189496d_2.html>. Acesso em 10 jan. 2020.

SHARPE, Jim. A história vista de baixo. In: BURKE, Peter (Org.). A escrita da história: novas perspectivas. São Paulo: UNESP, 1992, p. 39-62.

SOMMER, Doris. Ficções de fundação: os romances nacionais da América Latina. Trad. Gláucia Renate Gonçalves e Eliana Lourenço de Lima Reis. Belo Horizonte: Editora UFMG, 2004.

WEINHARDT, Marilene. Romance histórico: das origens escocesas ao Brasil finissecular. In: WEINHARDT, Marilene (Org.). Ficção histórica: teoria e crítica. Ponta Grossa: Editora UEPG, 2011, p. 12-55. 